\title{
Effect of trabeculectomy on ocular higher-order aberrations in patients with open angle glaucoma
}

\author{
Ali Mahdavi Fard, Rana Daei Sorkhabi, Kamal Nasiri, Arezou Tajlil \\ Department of Ophthalmology, Tabriz University of Medical Sciences, Tabriz, Iran
}

\begin{abstract}
OBJECTIVE: The aim of this study was to evaluate the effect of trabeculectomy on ocular higher-order aberrations following surgery in a group of patients with open angle glaucoma.

METHODS: In this prospective study, patients with primary open angle glaucoma underwent wavefront aberrometry before trabeculectomy with mitomycin-C. Coma-like, spherical-like, and total ocular higher-order aberrations were measured as root mean square values. The measurements were repeated 1 month and 3 months after the procedure.

RESULTS: A total of 20 eyes from 20 patients were examined. There was a significant decrease in intraocular pressure following surgery at 1 month and 3 months postoperatively. However, there was no statistically significant change in the spherical equivalent of the eyes. One month after surgery, a significant change in coma-like, spherical-like, and total higher-order aberrations of the eyes was observed. However, the repeated measurements performed 3 months after procedure revealed no significant difference compared to the baseline values.
\end{abstract}

CONCLUSION: Ocular higher-order aberrations increased 1 month following trabeculectomy surgery. However, this effect seems to be transient, as the values returned to the preoperative measurement 3 months after the procedure.

Keywords: Aberrometry; glaucoma; higher-order aberration.

G laucoma is a progressive neuropathy of the optic nerve which can lead to irreversible visual impairment. So far, lowering intraocular pressure (IOP), which can be achieved either with medication or surgery, is the most useful approach to protect the optic nerve. One of the most effective procedures for lowering IOP is trabeculectomy, with or without anti-fibrotic agents. On the other hand, many patients report changes in their vision following trabeculectomy surgery, such as choroidal detachment, corneal decompensation, hypotony, maculopathy and infection [1-8], which may be complications of the surgery, or, as in other ocular surgeries, including intraocular lens implantation and cataract extraction [911], scleral buckling [12], or pterygium excision [13], may be the result of changes in refractive state or higherorder aberrations [14-16] of the eye. The present study is an evaluation of the impact of trabeculectomy surgery on ocular higher-order aberrations.

\section{MATERIALS AND METHODS}

This study was approved by the institutional review board of Tabriz University of Medical Sciences and was conducted in accordance with the Declaration of Helsinki. All study patients gave written informed consent for their participation in this study. Patients with primary open angle glaucoma who had received the maximal nonsurgical treatment, including topical anti-glaucoma medications and laser therapy, and who were candidates for trabeculectomy with mitomycin-C (MMC) surgery and had been referred to the glaucoma clinic were considered for enrollment. Patients were included if they had corrected visual acuity of $\geq 20 / 40$, were free of significant cataract, had good cooperation for aberrometry, and had a dilated pupil diameter of $\geq 4 \mathrm{~mm}$. Patients with secondary glaucoma and angle closure glaucoma were excluded from the study. Additionally, patients with a prior 
history of ocular surgery or ocular disease other than glaucoma were not considered for participation. Patients underwent a detailed ophthalmic examination of the anterior and posterior segments of the eye with IOP measurement using standard applanation tonometry, as well as aberrometry measurements with I- trace aberrometer and refraction. Trabeculectomy surgery procedures were performed by 2 surgeons (AMF and RDS) using the same technique. After fashioning a fornix base conjunctival flap, a partial thickness scleral flap was created. MMC with a concentration of $0.4 \%$ was applied for 2 minutes, and after copious irrigation a paracentesis was performed. Following a sclerostomy, a peripheral iridectomy was performed and the scleral flap was closed with 10/0 nylon sutures. After checking for oozing through the scleral flap, the conjunctiva was sutured with $10 / 0$ nylon. At the end of the procedure, the wound was controlled for leakage and a subconjunctival injection of betamethasone, cefazolin, and atropine was administered. Patients underwent a thorough ophthalmological examination, including the anterior and posterior segments of the eye and IOP measurement the day after surgery and were discharged with topical betamethasone, ciprofloxacin, and homatropin to be administered 4 times a day. One week after surgery, patients underwent an ophthalmological examination with IOP control and conjunctival suture removal. At 1 month and 3 months after surgery the patients again underwent an ophthalmological examination and IOP control, as well as aberrometry with the same aberrometer unit. The wave-front aberrations were measured in a $4-\mathrm{mm}$ pupil area and the data were expanded to Zernike polynomials. The magnitude was demonstrated as root mean square (RMS). The RMS of the third-order Zernike coefficients (the square root of the sum of the squared coefficients of $\mathrm{C}_{3}^{-3}, \mathrm{C}_{3}^{-1}, \mathrm{C}_{3}{ }^{1}$, and $\mathrm{C}_{3}^{3}$ ) was considered a coma-like aberration, and the RMS of the fourth-order Zernike coefficients (the square root of the sum of the squared coefficients of $\mathrm{C}_{4}^{-4}, \mathrm{C}_{4}^{-2}, \mathrm{C}_{4}{ }^{0}, \mathrm{C}_{4}^{2}$, and $\mathrm{C}_{4}^{4}$ ) was considered a spherical-like aberration. The total of higher-order aberrations was defined as the RMS of the magnitudes for the third-order and forth-order aberrations.

\section{Statistical analysis}

The categorical variables are presented as frequencies and percentages, while continuous variables are shown as mean \pm SD. Preoperative and postoperative values were compared using analysis of variance. The recorded data were analyzed with IBM SPSS Statistics for Windows, Version 22.0. (IBM Corp., Armonk, NY, USA) software and a $\mathrm{p}$ value of less than 0.05 was considered statistically significant.

\section{RESULTS}

Twenty eyes from 20 patients with primary open angle glaucoma were included in the study. In all, 11 (55\%) patients were male and $9(45 \%)$ were female. The patients' age ranged from 46 to 78 years (mean age $61 \pm 9.3$ years) and all of them had a Snellen visual acuity of more than 20/40. All the patients underwent trabeculectomy with $\mathrm{MMC}$ without any surgery-related complication such as hypotony, poor IOP control, infection, or gross choroidal detachment. During the follow-up period, none of the participants developed a significant cataract or visual loss. The mean preoperative IOP was $29.1 \pm 6.4 \mathrm{mmHg}$, and at postoperative 1 month and 3 months, the mean IOP was $13.98 \pm 3.8$ and $13.1 \pm 3.6 \mathrm{mmHg}$, respectively. The change in IOP after surgery at all time points was significant in comparison with preoperative measurements $(\mathrm{p}<0.0001)$; however, the difference in IOP between 1 month and 3 months after surgery was statistically insignificant $(p=0.453)$. The mean spherical equivalent of refractive errors before surgery was $-1.65 \pm 1.35 \mathrm{D}$ and for 1 month and 3 months after surgery it was $-1.81 \pm 1.63$ $\mathrm{D}$ and $-1.97 \pm 1.45 \mathrm{D}$, respectively. Again, there was not a significant change in spherical equivalent before and after surgery $(p=0.737 ; 95 \%$ confidence interval $[C I]-0.798$ to 1.118 and $p=0.575 ; 95 \%$ CI -0.646 to 1.146 , respectively).

Preoperative and 1 month and 3 month postoperative ocular aberrations are reported in Table 1 . The mean ocular coma-like RMS value before surgery was $0.23 \pm 0.13$, and 1 month and 3 months after surgery, it was $0.34 \pm 0.15$ and $0.31 \pm 0.13$, respectively. The difference between the preoperative and 1 month postoperative values was statistically significant $(p=0.017 ; 95 \%$ CI -0.192 to -0.028 ); however, 3 months postoperative it was not statistically significant $(p=0.059$; (95\% CI -0.164 to 0.003$)$. The mean ocular spherical-like RMS value before surgery was $0.12 \pm 0.07$, and 1 month and 3 months after surgery it was $0.19 \pm 0.08$ and $0.16 \pm 0.08$, respectively. The difference between the preoperative and 1 month postoperative values was statistically significant ( $p=0.005 ; 95 \%$ CI -0.117 to- 0.023 ); however, 3 months postoperative it was not statistically significant ( $p=0.113 ; 95 \%$ CI -0.086 to 0.008$)$. The mean ocular total RMS value before surgery was $0.47 \pm 0.26$, and 1 month and 3 months after surgery it was $0.70 \pm 0.34$ and $0.60 \pm 0.25$, respectively. The difference between the pre- 
TABLE 1. Mean intraocular pressure, spherical equivalent, and root mean square of higher-order aberration values measured preoperatively and at 1 and 3 months postoperatively

\begin{tabular}{|c|c|c|c|c|c|}
\hline & Preoperative & $\begin{array}{c}1 \text { month } \\
\text { Postoperative }\end{array}$ & $\begin{array}{c}3 \text { months } \\
\text { Postoperative }\end{array}$ & $\begin{array}{c}\mathrm{p} \\
\text { (preop and } \\
1 \mathrm{~m} \text { post op) }\end{array}$ & $\begin{array}{c}\mathrm{p} \\
\text { (preop and } \\
\text { 3m post op) }\end{array}$ \\
\hline Mean IOP $(\mathrm{mmHg})$ & $29 \pm 6.40$ & $13.98 \pm 3.8$ & $13.1 \pm 3.6$ & $p<0.0001$ & $p<0.0001$ \\
\hline Mean spherical equivalent (D) & $-1.65 \pm 1.35$ & $-1.63 \pm 1.81$ & $-1.97 \pm 1.45$ & $p=0.737$ & $P=0.575$ \\
\hline Mean coma-like aberration RMS & $0.23 \pm 0.13$ & $0.34 \pm 0.15$ & $0.31 \pm 0.13$ & $P=0.017$ & $P=0.059$ \\
\hline Mean spherical-like aberration RMS & $0.12 \pm 0.07$ & $0.19 \pm 0.08$ & $0.16 \pm 0.08$ & $P=0.005$ & $P=0.113$ \\
\hline Mean total ocular higher order aberration RMS & $0.47 \pm 0.26$ & $0.70 \pm 0.34$ & $0.60 \pm 0.25$ & $P=0.023$ & $P=0.113$ \\
\hline
\end{tabular}

IOP: Intraocular pressure; m: Month; preop: Preoperative; postop: Postoperative; RMS: Root mean square; SE: Spherical equivalent.

operative and 1 month postoperative values was statistically significant $(\mathrm{p}=0.023 ; 95 \%$ CI -0.427 to -0.031$)$; however, 3 months postoperative it was not statistically significant ( $\mathrm{p}=0.113 ; 95 \%$ CI -0.291 to 0.033$)$.

\section{DISCUSSION}

Several studies have demonstrated that ocular surgeries such as intraocular lens implantation and cataract extraction [9-11], scleral buckling [12], and pterygium excision [13] may result in changes in the refractive state or higher-order aberrations [14-16] in the affected eye. In the present study, consistent with previous studies, we report similar changes in ocular higher-order aberrations 1 month postoperatively. However, no significant change was observed 3 months after the surgery. A prospective study found that 1 week after trabeculectomy surgery, $94 \%$ and $43 \%$ of patients reported a change in their uncorrected and corrected Snellen visual acuity, respectively [17]. Some studies have attributed these alterations in visual acuity to changes in corneal contour, anterior chamber depth, axial length of the globe, and thickness of the crystalline lens $[6,18-23]$. Another study demonstrated with vector analysis that the cylinder component of refraction was increased by $1.4 \mathrm{D}$; however, the vector power of surgically induced refractive change at 1 month postoperatively did not significantly correlate with corneal coma-like, spherical-like, or total RMS, suggesting that changes other than anterior corneal aberration, such as internal optics of the eye, play a role in the changes in higher-order aberrations postoperatively[14]. Francis et al. [23] reported a decrease in the axial length of the globe following trabeculectomy that was more prominent 1 week and 1 month after surgery, and suggested over-filtration as the explanation for their finding; however, similar to our findings, Fukuoka et al. [14] have shown that despite the stability of IOP from 1 month to 3 months postoperatively, the values of ocular coma-like, spherical-like, and total higher order aberrations changed during this time period and reached values similar to preoperative measures. Accordingly, we can conclude that changes in the internal optics of the eye due to factors such as iridocyclitis, macular edema, retinal hemorrhage, and scleral and choroidal thickness that may occur due to hypotony and surgical manipulation of ocular tissues, independent of IOP, are responsible for the alterations in higher-order aberrations. [24] In a prospective study by Karasheva and et al. [22] it was demonstrated that macular thickness increases 1 month after surgery, but subsides 3 months postoperatively and reaches the preoperative value. Furthermore, there was not a significant correlation between IOP and retinal thickness, and they concluded that even in the absence of ocular hypotony, macular edema may occur following trabeculectomy. In a study conducted by Martinez-Bello [25], $12.5 \%$ of the eyes developed suprachoroidal fluid in 3 to 6 months following trabeculectomy, which was detectable with ultrasound biomicroscopy. They hypothesized that it might have resulted from traction of the iris root during peripheral iridectomy and low IOP on the removal of the deep scleral block. Moreover, Sugimoto et al. [26] reported even higher rates of suprachoroidal fluid (33\%) following trabeculectomy in the absence of any intraocular inflammation and changes in anterior chamber depth or gross choroidal detachment within 2 weeks after surgery. These findings indicate that suprachoroidal fluid may appear more commonly and at an earlier stage than 3 or 6 months postoperatively and 
may dissolve soon after. Crystalline lens position and the thickness and anterior chamber depth can temporarily be changed following ciliary body edema due to surgical manipulation [14].

\section{Limitations}

The present study is limited by the relatively small number of patients and the lack of a control group. Additionally, we did not evaluate corneal higher-order aberrations along with ocular aberrations.

\section{CONCLUSION}

The results of this study are consistent with previous reports, and demonstrate the effect of trabeculectomy surgery on the optical system of the eye. Furthermore, the data suggest that the observed changes in the optics of the eye are transient and will most probably resolve in 3 months after surgery. Accordingly, any visual changes observed after this period cannot be attributed to the effect of surgery and would mandate comprehensive evaluation.

Conflict of Interest: No conflict of interest was declared by the authors.

Financial Disclosure: The authors declared that this study has received no financial support.

Authorship contributions: Concept - A.M.F., R.D.S., K.N., A.T.; Design - A.M.F., R.D.S., K.N., A.T.; Supervision - A.M.F., R.D.S.; Materials - A.M.F., R.D.S., K.N., A.T. Data collection \&/or processing - A.M.F., R.D.S., K.N., A.T.; Analysis and/or interpretation - A.M.F., R.D.S., K.N., A.T.; Writing - A.M.F., R.D.S., K.N., A.T.; Critical review - A.M.F., R.D.S.

\section{REFERENCES}

1. Zacharia PT, Deppermann SR, Schuman JS. Ocular hypotony after trabeculectomy with mitomycin C. Am J Ophthalmol 1993;116:314-26.

2. Sun X, Dai Y, Chen Y, Yu DY, Cringle SJ, Chen J, et al. Primary angle closure glaucoma: What we know and what we don't know. Prog Retin Eye Res 2017;57:26-45. [CrossRef]

3. Shigeeda T, Tomidokoro A, Chen YN, Shirato S, Araie M. Long-term follow-up of initial trabeculectomy with mitomycin C for primary open-angle glaucoma in Japanese patients. J Glaucoma 2006;15:195-9.

4. Seah SK, Prata JA Jr, Minckler DS, Baerveldt G, Lee PP, Heuer DK. Hypotony following trabeculectomy. J Glaucoma 1995;4:73-9. [CrossRef]

5. Reibaldi A, Uva MG, Longo A. Nine-year follow-up of trabeculectomy with or without low-dosage mitomycin-c in primary open-angle glaucoma. Br J Ophthalmol 2008;92:1666-70. [CrossRef]

6. Leeungurasatien T, Khunsongkiet P, Pathanapitoon K, Wiwatwongwana $\mathrm{D}$. Incidence of short-term complications and associated factors after primary trabeculectomy in Chiang Mai University Hospital. Indian J Ophthalmol 2016;64:737-42. [CrossRef]
7. Jongsareejit B, Tomidokoro A, Mimura T, Tomita G, Shirato S, Araie M. Efficacy and complications after trabeculectomy with mitomycin $C$ in normal-tension glaucoma. Jpn J Ophthalmol 2005;49:223-7. [CrossRef]

8. Hagiwara Y, Yamamoto T, Kitazawa Y. The effect of mitomycin C trabeculectomy on the progression of visual field defect in normal-tension glaucoma. Graefes Arch Clin Exp Ophthalmol 2000;238:232-6.

9. Mojzis P, Majerova K, Plaza-Puche AB, Hrckova L, Alio JL. Visual outcomes of a new toric trifocal diffractive intraocular lens. J Cataract Refract Surg 2015;41:2695-706. [CrossRef]

10. Song IS, Park JH, Park JH, Yoon SY, Kim JY, Kim MJ, et al. Corneal coma and trefoil changes associated with incision location in cataract surgery. J Cataract Refract Surg 2015;41:2145-51. [CrossRef]

11. Oshika T, Sugita G, Miyata K, Tokunaga T, Samejima T, Okamoto $\mathrm{C}$, et al. Influence of tilt and decentration of scleral-sutured intraocular lens on ocular higher-order wavefront aberration. $\mathrm{Br} \mathrm{J}$ Ophthalmol 2007;91:185-8. [CrossRef]

12. Okamoto F, Yamane N, Okamoto C, Hiraoka T, Oshika T. Changes in higher-order aberrations after scleral buckling surgery for rhegmatogenous retinal detachment. Ophthalmology 2008;115:1216-21. [CrossRef]

13. Gumus K, Topaktas D, Göktaş A, Karakucuk S, Oner A, Mirza GE. The change in ocular higher-order aberrations after pterygium excision with conjunctival autograft: a 1-year prospective clinical trial. Cornea 2012;31:1428-31. [CrossRef]

14. Fukuoka S, Amano S, Honda N, Mimura T, Usui T, Araie M. Effect of trabeculectomy on ocular and corneal higher order aberrations. Jpn J Ophthalmol 2011;55:460-6. [CrossRef]

15. Dietze PJ, Oram O, Kohnen T, Feldman RM, Koch DD, Gross RL. Visual function following trabeculectomy: effect on corneal topography and contrast sensitivity. J Glaucoma 1997;6:99-103. [CrossRef]

16. Claridge KG, Galbraith JK, Karmel V, Bates AK. The effect of trabeculectomy on refraction, keratometry and corneal topography. Eye (Lond) 1995;9:292-8. [CrossRef]

17. Shigeeda T, Tomidokoro A, Araie M, Koseki N, Yamamoto S. Longterm follow-up of visual field progression after trabeculectomy in progressive normal-tension glaucoma. Ophthalmology 2002;109:766-70.

18. Rosen WJ, Mannis MJ, Brandt JD. The effect of trabeculectomy on corneal topography. Ophthalmic Surg 1992;23:395-8.

19. Rasooly R, Benjamin L, Casson R. Change in lens thickness after trabeculectomy. Int Ophthalmol 2001;24:25-6. [CrossRef]

20. Németh J, Horóczi Z. Changes in the ocular dimensions after trabeculectomy. Int Ophthalmol 1992;16:355-7. [CrossRef]

21. Kook MS, Kim HB, Lee SU. Short-term effect of mitomycin-C augmented trabeculectomy on axial length and corneal astigmatism. J Cataract Refract Surg 2001;27:518-23. [CrossRef]

22. Karasheva G, Goebel W, Klink T, Haigis W, Grehn F. Changes in macular thickness and depth of anterior chamber in patients after filtration surgery. Graefes Arch Clin Exp Ophthalmol 2003;241:170-5. [CrossRef]

23. Francis BA, Wang M, Lei H, Du LT, Minckler DS, Green RL, et al. Changes in axial length following trabeculectomy and glaucoma drainage device surgery. Br J Ophthalmol 2005;89:17-20. [CrossRef]

24. Cunliffe IA, Dapling RB, West J, Longstaff S. A prospective study examining the changes in factors that affect visual acuity following trabeculectomy. Eye (Lond) 1992;6:618-22. [CrossRef]

25. Martínez-Belló C, Capeáns C, Sánchez-Salorio M. Ultrasound biomicroscopy in the diagnosis of supraciliochoroidal fluid after trabeculectomy. Am J Ophthalmol 1999;128:372-5. [CrossRef]

26. Sugimoto K, Ito K, Esaki K, Miyamura M, Sasoh M, Uji Y. Supraciliochoroidal fluid at an early stage after trabeculectomy. Jpn J Ophthalmol 2002;46:548-52. [CrossRef] 